\title{
The correlation between endometriosis and metabolic syndrome
}

\author{
Nicolae Bacalbasa ${ }^{1,2,3}$, Irina Balescü, Mihaela Vilcu ${ }^{2,3}$, Simona Dima1, \\ Iulian Brezean ${ }^{2,3}$ \\ ${ }^{1}$ Center of Excellence in Translational Medicine, Fundeni Clinical Institute, Bucharest, Romania \\ 2"Carol Davila" University of Medicine and Pharmacy, Bucharest, Romania \\ 3"Ion Cantacuzino" Clinical Hospital, Bucharest, Romania \\ ${ }^{4}$ Ponderas Academic Hospital, Bucharest, Romania
}

\begin{abstract}
Although it represents a benign condition, endometriosis is an important and sometimes debilitating health problem affecting women worldwide, associated with a high capacity of relapse. While the correlation between different endometrial pathologies, obesity and metabolic syndrome has been clearly demonstrated lately, the relationship between endometriosis and metabolic syndrome is far to be understood. The aim of this paper is to review the most relevant studies conducted on this issue.
\end{abstract}

Keywords: endometriosis, estrogen, obesity, metabolic syndrome

\section{INTRODUCTION}

Endometriosis represents an estrogen dependent gynecological disorder characterized by the presence of endometrial like tissue outside the uterine cavity and is estimated that it affects up to $11 \%$ of fertile women worldwide (1). Unfortunately this disorder is associated with pelvic pain, infertility, constipation, oxidative stress, inflammation, ovarian, breast or even endometrial cancer $(2,3)$. However, the pathogenic mechanisms as well as the risk factors for developing this disease are not clearly understood, multiple theories being reported so far. Moreover, although multiple therapeutic strategies have been proposed, most patients will develop recurrent disease; in this context, understanding the most important pathogenic mechanisms seem to play a central role in order to control the local evolution of the disease (4).

\section{EPIDEMIOLOGICAL RISK FACTORS FOR ENDOMETRIOSIS DEVELOPMENT}

The incidence of endometriosis among women worldwide was studied in various papers, in order to determine which the most important epidemiological risk factors are. Therefore, it seems that taller height and lesser weight might increase the chances of developing this disease (5-7). In consequence, these studies came to demonstrate that a lower body mass index (BMI) is associated with a higher risk of endometriosis (5-7). A meta-analysis conducted by Liu Y et al. on 11 such studies stated that obesity is significantly associated with a lower risk of endometriosis development, a 33\% reduction of the endometriosis risk being observed for each $5 \mathrm{~kg} / \mathrm{m}^{2}$ increase of the BMI. In the meantime the authors underlined the fact that is not clearly understood whether endometriotic disease is not underdiagnosed in obese patients due to the higher difficulty of establishing a correct diagnostic in cases with significantly higher values of the BMI (8). However, further studies came to demonstrate that the correlation between adiposity and endometriosis is more complex (9). Therefore, it seems that endometriosis is rather correlated with the distribution of the adipose tissue below waist (10). Therefore, in a systematic review conducted by Backonja et al. in 2016 the authors included 19 studies and demonstrated that peripheral adiposity (defined by 
the presence of fat tissue below waist) is a significant risk factor for endometriosis development (10).

However all theories regarding the correlation between endometriosis and lower BMI values (according to which a lower BMI is a risk factor for developing endometriosis) were destroyed by the study conducted by Byun et al. which came to demonstrate that the relation the causality is in fact an inverse one; according to this study, endometriosis is responsible for alteration of the hepatic metabolism and further induces other metabolic changes which will lead to weight loss. This conclusion was drawn after analyzing the correlation between adiposity, typology and severity of endometriosis on a group of 473 patients (9).

In the meantime it seems that the correlation between BMI and endometriosis development is also significantly influenced by race; for example, a study conducted among Taiwanese women came to demonstrate that Taiwanese women with endometriosis are more likely to be obese and to develop type II diabetes mellitus (11).

An interesting study which aimed to analyze the correlation ship between BMI and the incidence and respectively the severity of endometriosis has been recently published by Holdsworth-Carsons et al.; the study underlined the fact that although obesity seems to be associated with lower rates of endometriosis development, obese women presenting this pathology trend to develop more severe forms of diseases; therefore, the authors proposed to use the BMI values to sub-classify this disease (12).

\section{THE CORRELATION BETWEEN ENDOMETRIOSIS AND ATHEROSCLEROTIC DISEASE}

Another interesting aspect which has been widely studied is the correlation between endometriosis and atherosclerotic disease. Therefore it has been widely demonstrated that endometriosis is implicated in processes which induce a degree of chronic systemic inflammation, increased oxidative stress and modification of the lipid profile leading to the development of atherosclerotic disease (13). One of the largest studies which were conducted on the theme of the correlation between atherosclerosis and endometriosis has been recently published by Tan et al. and demonstrated that women presenting endometriosis are at risk to associate dyslipidemia, atherosclerosis and arterial hypertension; this fact was mainly explained by the presence of higher amounts of circulating inflammatory mediators (14).

\section{THE INFLUENCE OF CIRCULATING ESTROGEN ON ENDOMETRIOSIS DEVELOPMENT}

It has been widely demonstrated that an excess of estrogen will lead to the apparition of particular gynecological conditions such as ovarian cysts, ovarian polycystic syndrome, endometrial hyperplasia, endometrial cancer, uterine fibroids as well as of endometriosis (15). Moreover, estrogen seems to be highly expressed in endometriosis lesions when compared to normal endometrium; therefore certain genetic studies came to demonstrate that there is a strong influence between polymorphisms in estrogen-related genes and excess adiposity and even higher BMI; this correlation would further explain the strong relationship between genetic modifications, estrogen level, higher BMI and endometriosis development (16).

\section{THE INFLUENCE OF OBESITY AND METABOLIC SYNDROME ON THE ENDOMETRIAL PATHOLOGY}

When it comes to the influence of obesity and circulating estrogen on pre-existing endometrial pathology, things are more clearly defined; therefore, it has been widely demonstrated that obesity induced the presence of excess of estrogen, creating in this way a stimulation at the endometrial lining; therefore, endometrial cell might present anarchic division and proliferation, conducting to the apparition of premalignant and even malignant conditions (17-19).

In a study conducted by Modesitt et al. on a group of 71 women proposed for bariatric surgery, the authors demonstrated that three cases also associated premalignant conditions - simple or complex endometrial hyperplasia; in the meantime the same authors reported that after performing a bariatric procedure, these modifications improved or disappeared, demonstrating in this way the potential benefit of bariatric surgery on endometrial cancer development (20).

When it comes to the potential benefit of bariatric surgery on endometriosis, no clear point of view is available yet due to the fact that there is no clear correlation between body mass index and endometriosis. However, since recent studies came to demonstrate that the severity of endometriosis might be in fact associated with higher BMI values, further studies are expected in order to determine whether performing a bariatric procedure in an 
obese patient with severe endometriosis might induce the alleviation of the endometriotic disease (similarly to the effect which has been proven for premalignant uterine pathologies).

\section{CONCLUSIONS}

The correlation ship between endometriosis, metabolic syndrome, body mass index and circulating estrogen is a very complex one, multiple factors influencing this relationship. Although initially it has been considered that a lower BMI represents a risk factor for endometriosis development (due to the fact that the gynecological pathology is more frequently in under weighted or normal weighted females), this myth was destroyed by the observa- tion according to which most probably endometriosis itself induces weight loss. In the meantime a strong correlation has been observed between the levels of circulating estrogen and the inflammatory status, respectively atherosclerotic disease and endometriosis. However, further studies are still needed in order to clarify these connections.

\section{Acknowledgement}

This work was supported by the project entitled „Multidisciplinary Consortium for Supporting the Research Skills in Diagnosing, Treating and Identifying Predictive Factors of Malignant Gynecologic Disorders", project number PN-III-P1-1.2-PCCDI2017-0833.

\section{REFERENCES}

1. Buck Louis GM, Hediger ML, Peterson CM, Croughan M, Sundaram R, Stanford J, Chen Z, Fujimoto VY, Varner MW, Trumble A, Giudice LC. Incidence of endometriosis by study population and diagnostic method: The ENDO study. Fertil.Steril. 2011; 96:360-365.

2. Vercellini P, Vigano P, Somigliana E, Fedele L. Endometriosis: pathogenesis and treatment. Nat.Rev.Endocrinol. 2014; 10:261-275.

3. Kvaskoff M, Mu F, Terry KL, Harris HR, Poole EM, Farland L, Missmer SA. Endometriosis: A high-risk population for major chronic diseases? Hum.Reprod.Update. 2015; 21: 500-516.

4. Shafrir AL, Farland LV, Shah DK, Harris HR, Kvaskoff M, Zondervan $\mathrm{K}$, Missmer S A. Risk for and consequences of endometriosis: A critical epidemiologic review. Best.Pract.Res. Clin.Obstet.Gynaecol. 2018; 51: 1-15.

5. Moini A, Malekzadeh F, Amirchaghmaghi E, Kashfi F, Akhoond MR, Saei M, Mirbolok MH. Risk factors associated with endometriosis among infertile Iranian women. Arch.Med.Sci. 2013; 9: 506-514.

6. Hemmings R, Rivard M, Olive DL, Poliquin-Fleury J, Gagne D, Hugo $\mathrm{P}$, Gosselin D. Evaluation of risk factors associated with endometriosis. Fertil.Steril. 2004; 81: 1513-1521.

7. Signorello LB, Harlow BL, Cramer DW, Spiegelman D, Hill JA. Epidemiologic determinants of endometriosis: A hospital-based case-control study. Ann.Epidemiol. 1997; 7: 267-741.

8. Liu Y, Zhang W. Association between body mass index and endometriosis risk: A meta-analysis. Oncotarget. 2017; 8: 4692846936.

9. Byun J, Peterson CM, Backonja U, Taylor RN, Stanford JB, Allen-Brady KL, Smith K R, Louis GMB, Schliep KC. Adiposity and Endometriosis Severity and Typology. J.Minim.Invasive.Gynecol. 2020.

10. Backonja U, Buck Louis G M, Lauver D R. Overall Adiposity, Adipose Tissue Distribution, and Endometriosis: A Systematic Review. Nurs. Res. 2016; 65: 151-166.

11. Teng SW, Horng HC, Ho CH, Yen MS, Chao HT, Wang PH. Women with endometriosis have higher comorbidities: Analysis of domestic data in Taiwan. J.Chin Med.Assoc. 2016; 79: 577-582.
12. Holdsworth-Carson SJ, Dior UP, Colgrave EM, Healey M, Montgomery GW, Rogers PAW, Girling JE. The association of body mass index with endometriosis and disease severity in women with pain. Journal of Endometriosis and Pelvic Pain Disorders. 2018; 10: 79-87.

13. de Ziegler D, Borghese B, Chapron C. Endometriosis and infertility: pathophysiology and management. Lancet 2010; 376: 730-738.

14. Tan J, Taskin O, lews M, Lee A J, Kan A, Rowe T, Bedaiwy MA. Atherosclerotic cardiovascular disease in women with endometriosis: A systematic review of risk factors and prospects for early surveillance. Reprod.Biomed.Online. 2019; 39: 1007-1016.

15. Zhang Q, Shen Q, Celestino J, Milam MR, Westin SN, Lacour RA, Meyer LA, Shipley GL, Davies PJ, Deng L, McCampbell AS, Broaddus $\mathrm{RR}$, Lu KH. Enhanced estrogen-induced proliferation in obese rat endometrium. Am.J.Obstet.Gynecol. 2009; 200: 186-188.

16. Cardoso JV, Abrao MS, Berardo PT, Ferrari R, Nasciutti LE, Machado DE, Perini J A. Role of cytochrome P450 2C19 polymorphisms and body mass index in endometriosis: A case-control study. Eur.J.Obstet. Gynecol.Reprod.Biol. 2017; 219: 119-123.

17. Modesitt S, Walker J. Obesity crisis in cancer care: gynecologic cancer prevention, treatment, and survivorship in obese women in the United States. Gynecol.Oncol. 2014; 133: 1-3.

18. Flegal KM, Carroll M D, Kit BK, Ogden CL. Prevalence of obesity and trends in the distribution of body mass index among US adults, 1999-2010. JAMA 2012; 307: 491-497.

19. Reeves GK, Pirie K, Beral V, Green J, Spencer E, Bull D. Cancer incidence and mortality in relation to body mass index in the Million Women Study: Cohort study. BMJ 2007; 335: 1134.

20. Modesitt SC, Hallowell PT, Slack-Davis JK, Michalek RD, Atkins KA, Kelley SL, Arapovic S, Shupnik MA, Hoehn K. Women at extreme risk for obesity-related carcinogenesis: Baseline endometrial pathology and impact of bariatric surgery on weight, metabolic profiles and quality of life. Gynecol.Oncol. 2015; 138: 238-245. 